\title{
Active surveillance voor prostaatkanker: vergelijking van uitkomsten tussen patiënten die wel of niet aan de PRIAS-criteria voldoen
}

\author{
Timo F. W. Soeterik' • Harm H. E. van Melick² - Lea M. Dijksman³ • Douwe H. Biesma ${ }^{3}$. J. A. (Fred) Witjes ${ }^{4}$. \\ Jean-Paul A. van Basten ${ }^{5}$
}

Published online: 9 September 2019

(c) The Author(s) 2019

\section{Samenvatting}

Er is onvoldoende bekend over de prognose van patiënten met prostaatkanker onder active surveillance (AS) die niet aan de PRIAS-inclusiecriteria voldoen. In een cohort van 1.000 patiënten uit zes ziekenhuizen werd onderzocht of 'PRIAS-ongeschikte' patiënten onder AS een hogere kans hadden op een ongunstigere PA na radicale prostatectomie (RP) en op metastasen. Van de 1.000 patiënten voldeed circa de helft niet aan de PRIAS-criteria. Zij hadden significant eerder tumorprogressie en een verhoogd risico op een positief snijvlak en ongunstige histologische uitkomsten na uitgestelde RP, vergeleken met patiënten die wél aan de PRIAS-criteria voldeden. In de totale populatie werd verder vastgesteld dat PSA-densiteit $\geq 0,2$ een belangrijke individuele predictor is van biochemische progressie na RP en het ontwikkelen van metastasen.

Trefwoorden prostaatkanker · active surveillance $\cdot$ patiëntselectie $\cdot$ PSA $\cdot$ metastasen $\cdot$ prostatectomie

\section{Active surveillance for prostate cancer: comparison of PRIAS-eligible and PRIAS-ineligible patients}

\begin{abstract}
Little is known about the outcomes of off-protocol selected prostate cancer patients who opt for active surveillance. In our cohort of 1,000 patients, outcomes of PRIAS-eligible patients were compared with outcomes of PRIAS-ineligible patients. Unfavourable outcomes after radical prostatectomy (RP) and risk of metastasis were evaluated. 50\% of patients on AS did not comply with the PRIAS criteria. PRIAS-ineligible patients discontinued active surveillance due to tumour progression significantly earlier than PRIAS-eligible patients; they also had a higher risk of positive surgical margins and unfavourable histology after deferred RP. PSA density $\geq 0.2$ was the most important individual predictor and, in addition to a higher risk of tumour progression and unfavourable surgical outcomes, was also associated with a significantly higher risk of biochemical progression after deferred radical prostatectomy and a higher risk of metastasis.
\end{abstract}

Keywords prostate cancer $\cdot$ active surveillance $\cdot$ patient selection $\cdot$ PSA density $\cdot$ metastasis $\cdot$ prostatectomy

drs. Timo F. W. Soeterik

t.soeterik@antoniusziekenhuis.nl

1 afdeling Value-Based Healthcare, Santeon, Utrecht, Nederland

2 afdeling Urologie, St. Antonius Ziekenhuis, Nieuwegein/Utrecht, Nederland
3 afdeling Value-Based Healthcare, St. Antonius Ziekenhuis, Nieuwegein/Utrecht, Nederland

4 afdeling Urologie, Radboud Universitair Ziekenhuis, Nijmegen, Nederland

5 afdeling Urologie, Canisius Wilhelmina Ziekenhuis, Nijmegen, Nederland 


\section{Introductie}

Om te worden geselecteerd voor actieve surveillance (AS) in de grote prospectieve cohortstudies, waaronder Prostate Cancer Research International Active Surveillance (PRIAS), moeten patiënten met prostaatkanker (PCa) aan strikte inclusiecriteria voldoen. Het is vanuit de praktijk echter bekend dat mannen met een hoger risico, die niet aan al deze selectiecriteria voldoen, óók opteren voor AS. Patiënten met een hoger risico toch voor AS selecteren, kan verschillende redenen hebben, waaronder een sterke motivatie van een patiënt om continentie en erectiele functie te behouden [1].

Dit werd bevestigd in een onderzoek door het Michigan Urological Surgery Improvement Collaborative (MUSIC). In het onderzochte Amerikaanse cohort patiënten dat met AS werd behandeld, voldeed ongeveer de helft aan de selectiecriteria van een aantal andere grote AS-cohorten (o.a. die van Johns Hopkins, MSKCC en UCSF) [2, 3]. Er is inmiddels een goed beeld van het beloop en de uitkomsten van AS bij (zeer) laagrisicopatiënten in studieverband. Er is daarentegen veel minder bekend over de AS-uitkomsten van patiënten met $\mathrm{PCa}$ die vanwege een hoger risicoprofiel níet in aanmerking komen voor inclusie van deze onderzoeken. Om patiënten met een hoger risico adequaat te kunnen informeren over hun prognose wanneer zij opteren voor $\mathrm{AS}$, is meer informatie nodig over de resultaten van AS op middellange en lange termijn van patiënten met een hoger risico op baseline.

Het doel van deze studie was een beeld te krijgen van het risicoprofiel van patiënten met prostaatkanker die worden vervolgd volgens het AS-principe. Als belangrijkste uitkomstmaat hiervoor hebben we geëvalueerd welk percentage patiënten in een Nederlandse populatie met prostaatkanker onder AS niét aan de PRIAS-criteria voldoen [4]. Tevens onderzochten wij of het beloop bij patiënten die niet geschikt waren voor PRIAS anders was vergeleken met patiënten die wél aan de PRIAS-criteria voldeden.

\section{Materiaal en methode}

\section{Setting en datacollectie}

Deze studie werd uitgevoerd binnen Santeon, een samenwerkingsverband tussen zeven topklinische ziekenhuizen. Alle patiënten die middels prostaatbiopsie waren gediagnosticeerd met PCa tussen 1 januari 2008 en 31 december 2014, en primair geïncludeerd waren voor AS, werden geëvalueerd. De patiëntgegevens werden geëxtraheerd uit de Santeon Prostaatkanker Cohort Database, die bestaat uit retrospectief verzamelde gegevens ter verbetering van de kwaliteit van zorg. In de onderzoeksperiode waren ge- gevens beschikbaar van zes van de zeven ziekenhuizen. Aanvullende gegevens over biochemische follow-up na in opzet curatieve behandeling, histologische en chirurgische uitkomsten van uitgestelde radicale prostatectomie en het optreden van metastasen werden verzameld door dossiermedewerkers, die werden geïnstrueerd door de hoofdonderzoeker (TS). Studiegegevens werden verzameld en beheerd met behulp van de online tool REDCap [5].

\section{Patiëntenpopulatie}

Patiënten werden geïncludeerd als ze onder AS waren, dat wil zeggen dat er een duidelijk onderscheid werd gemaakt tussen deze patiënten en patiënten die gevolgd werden zonder curatieve intentie (watchful waiting, of 'waakzaam wachten') [6]. Patiënten van 80 jaar of ouder, patiënten met incidentele tumoren $(\mathrm{T} 1 \mathrm{a} / \mathrm{b})$, patiënten met behandelstrategieën anders dan AS en patiënten die aanvankelijk werden behandeld in een ziekenhuis buiten het Santeon Consortium werden geëxcludeerd.

\section{Active surveillance follow-up}

AS werd als standaard beschouwd indien ze werd uitgevoerd volgens het PRIAS-follow-upprotocol. Dit protocol omvat een prostaatspecifieke antigeen (PSA) test plus een rectaal toucher om de 3-6 maanden, gecombineerd met een bevestigende biopsie één jaar na de diagnose en vervolgens om de drie jaar [7]. AS kan worden beëindigd vanwege ziekteprogressie (bijvoorbeeld een upgrade van Gleason) of om niet-oncologische redenen (bijvoorbeeld de voorkeur van de patiënt of het begin van andere ziekten die prognosebepalend zijn).

\section{Uitkomstmaten}

De primaire uitkomstmaat was het percentage patiënten dat niet voldeed aan een of meer van de PRIAS-toelatingscriteria (voor PRIAS ongeschikt). De PRIAS-criteria zijn: klinische fase T1c-T2, Gleason-somscore $\leq 6, \leq 2$ positieve biopten, PSA $\leq 10 \mathrm{ng} / \mathrm{ml}$ en PSA-densiteit (PSAD) $<0,2 \mathrm{ng} / \mathrm{ml} / \mathrm{ml}$ [4]. Secundaire uitkomstmaten omvatten het percentage patiënten met metastasen (bot en/of lymfeklier) en beëindiging van AS als gevolg van tumorprogressie. De resultaten van patiënten die een uitgestelde radicale prostatectomie ondergingen, werden afzonderlijk geanalyseerd. In deze subgroep evalueerden we het aantal patiënten met een zenuwsparende procedure, met positieve snijvlakken, ongunstige histologie (gedefinieerd als een pathologisch stadium $\geq \mathrm{T} 3 \mathrm{en} /$ of Gleason-somscore $\geq 8$ ). Ook werd de incidentie van biochemisch recidief (gedefinieerd als tweemaal PSA $\geq 0,2 \mathrm{ng} / \mathrm{ml}$ na radicale prostatectomie [8]) bij deze patiënten beoordeeld. 
Figuur 1 Percentage patiënten dat niet voldeed aan alle individuele en totale PRIAS-criteria $(n=1.000)$. PSA prostaatspecifiek antigen; PSAD PSA-densiteit; PRIAS Prostate Cancer Research International Active Surveillance

Tabel 1 Baselinekarakteristieken
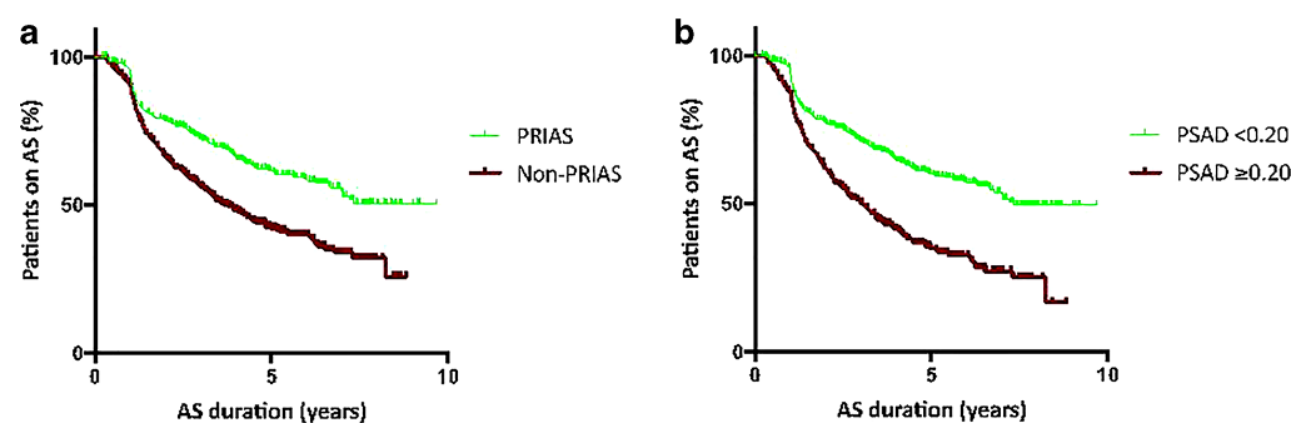

\begin{tabular}{lccc}
\hline & PRIAS-geschikt & PRIAS-ongeschikt & $p$ \\
\hline aantal patiënten & 510 & 490 & \\
leeftijd (jaren) & $66,3 \pm 0,3$ & $68,2 \pm 0,3$ & $<0,001$ \\
PSA (ng/ml) & $6,1 \pm 1,9$ & $10,2 \pm 5,5$ & $<0,001$ \\
PSA densiteit (ng/ml/ml) & $0,12 \pm 0,04$ & $0,25 \pm 0,14$ & $<0,001$ \\
cT-stadium (\%) & & & \\
$\quad$ T1c & $407(80)$ & $381(78)$ & \\
T2a & $40(8)$ & $24(5)$ & \\
T2b & $4(1)$ & $10(2)$ & \\
T2c & $6(1)$ & $9(2)$ & \\
T2 & $53(10)$ & $55(11)$ & \\
T3 & $0(0)$ & $11(2)$ & \\
totaal aantal biopsiescores & $9,2 \pm 1,9$ & $8,9 \pm 2,0$ & \\
aantal positieve biopten & $1,3 \pm 0,4$ & $2,1 \pm 1,3$ & \\
Gleason-score & & & \\
$2+2$ & $2(0)$ & $3(1)$ & \\
$2+3 / 3+2$ & $3(1)$ & $7(1)$ & \\
$3+3$ & $505(99)$ & $434(89)$ & \\
$3+4$ & 0 & 42 & \\
$4+3$ & 0 & 4 & \\
\hline
\end{tabular}

\section{Statistische analyse}

Univariabele en multivariabele Cox-regressieanalyse met backward elimination werden gebruikt voor vergelijking van uitkomsten tussen voor PRIAS geschikte en voor PRIAS ongeschikte patiënten. Analyse van tijd tot tumorprogressie (progressievrije overleving) werd uitgevoerd middels Kaplan-Meier-survivalanalyse. Analyses werden gedaan met behulp van SPSS V.24.0 (IBM Corp, Armonk, NY, VS).

\section{Resultaten}

\section{Patiëntenpopulatie}

In totaal werden 1.181 patiënten geëvalueerd, waarvan 181 patiënten werden geëxcludeerd wegens incidentele tumoren $(\mathrm{cT} 1 \mathrm{a} / \mathrm{b})$. In het resterende cohort van 1.000 mannen voldeed ongeveer de helft van de mannen ten tijde van de diagnose niet aan de PRIAS-inclusiecriteria, namelijk 490/1.000 (49\%). Van alle afzonderlijke criteria werd aan het criterium 'PSAD $<0,20$ ' het vaakst niet voldaan (31\%) (fig. 1). Baselinekenmerken van zowel voor PRIAS geschikte als voor PRIAS ongeschikte patiënten zijn weergegeven in tab. 1.

\section{Tijd tot tumorprogressie}

Bij 437 (44\%) van de 588 (59\%) patiënten bij wie AS gedurende de studieperiode werd beëindigd, gebeurde dit vanwege tumorprogressie. Redenen voor het beëindigen van AS zijn vermeld in tab. 2. Fig. 2 laat zien dat voor PRIAS ongeschikte patiënten significant eerder tumorprogressie kregen dan voor PRIAS geschikte patiënten. Dit verhoogde risico werd bevestigd door univariabele Cox-regressieanalyse (hazardratio $(\mathrm{HR})=1,74$; $95 \%-\mathrm{BI}=1,44-2,11)(\mathrm{tab} .3)$. 
Bovendien was zowel 'een PSAD $\geq 0,2$ ' als ' $>2$ biopten tumorpositief bij diagnose' een sterke voorspeller van tumorprogressie. Van deze twee criteria was een PSAD $\geq$ 0,2 de sterkste voorspeller in het multivariabele Cox-regressiemodel $(\mathrm{HR}=2,01 ; 95 \%-\mathrm{BI}=1,67-2,44)(\mathrm{tab} .3)$.

\section{Ongunstige uitkomsten na uitgestelde radicale prostatectomie}

Van alle 588 patiënten die AS beëindigden, ondergingen $420(71 \%)$ een in opzet curatieve behandeling. Van deze laatste patiënten ondergingen 182/420 (43\%) patiënten een radicale prostatectomie. Voor PRIAS ongeschikte patiënten hadden een significant hoger risico op ongunstige histologische uitkomsten (pT-stadium $\geq \mathrm{T} 3$ en/of Gleasonsomscore $>7$ ) en positieve chirurgische marges na uitgestelde prostatectomie (tab. 4) in vergelijking met voor PRIAS geschikte patiënten. Patiënten met een PSAD $\geq 0,2$ hadden een hoger risico op ongunstige histologie $(\mathrm{OR}=3,61 ; 95 \%-\mathrm{BI}=1,85-7,05)$, positieve chirurgische marges $(\mathrm{OR}=1,97 ; 95 \%-\mathrm{BI}=1,03-3,79)$ en biochemische progressie $(\mathrm{OR}=3,26 ; 95 \%-\mathrm{BI}=1,23-8,64)$.

\section{Associatie tussen een hoger baseline risicoprofiel en het ontwikkelen van metastasen}

De mediane follow-up (periode tussen de datum van diagnose en het laatste ziekenhuisbezoek) van het cohort was 5,0 $(\mathrm{IQR}=3,5-6,6)$ jaar. Tijdens deze follow-upperiode ontwikkelden 25 van de 1.000 mannen $(2,5 \%)$ metastasen. In tegenstelling tot onze eerdere resultaten hadden de voor PRIAS ongeschikte patiënten geen significant hoger risico op metastasen in vergelijking met de voor PRIAS geschikte patiënten $(\mathrm{HR}=1,37 ; 95 \%$-BI $=0,62-3,01)$.
Tabel 2 Redenen voor het beëindigen van de active surveillance (AS)

\begin{tabular}{|c|c|c|}
\hline reden & categorie & patiënten $(\%)$ \\
\hline \multirow{7}{*}{$\begin{array}{l}\text { oncologisch } \\
(n=437)\end{array}$} & PSA-kinetiek $^{\mathrm{a}}$ & $66(11)$ \\
\hline & rectaal toucher ${ }^{b}$ & $1(0)$ \\
\hline & Gleason-upgrading & $82(14)$ \\
\hline & biopsie tumorvolume $\uparrow^{\mathrm{c}}$ & $65(11)$ \\
\hline & MRI-bevindingen ${ }^{\mathrm{d}}$ & $19(3)$ \\
\hline & overig & $10(2)$ \\
\hline & combinatie 2 of meer & $194(33)$ \\
\hline \multirow{5}{*}{$\begin{array}{l}\text { niet-oncologisch } \\
(n=151)\end{array}$} & comorbiditeit/leeftijd $^{\mathrm{e}}$ & $41(7)$ \\
\hline & voorkeur patiënt & $24(4)$ \\
\hline & overig $^{\mathrm{f}}$ & $30(5)$ \\
\hline & lost to follow-up & $56(10)$ \\
\hline & totaal & $588(100)$ \\
\hline
\end{tabular}

a Bijvoorbeeld: PSADT $<3$ jaar en/of PSA $>10$

${ }^{\mathrm{b}} \mathrm{RT}=$ rectaal toucher

${ }^{\mathrm{c}}$ Er was $>50 \%$ tumorvolume in het biopt of er waren $\geq 3$ positieve biopten

${ }^{\mathrm{d}}$ Bijvoorbeeld T3, toename tumorvolume

${ }^{\mathrm{e}}$ Comorbiditeit die de prognose van de patiënt bepaalt of als de patiënt een leeftijd bereikt waarbij de aanwezigheid van de tumor niet klinisch relevant is

${ }^{\mathrm{f}}$ Bijvoorbeeld mictieklachten of terugverwijzing naar de huisarts

Patiënten met een PSAD $\geq 0,2$ hadden een significant hoger risico op metastasen in vergelijking met patiënten met een PSAD $<0,2(\mathrm{HR}=2,71 ; 95 \%-\mathrm{BI}=1,23-5,96)$. Patiënten die aan minder dan twee PRIAS-criteria voldeden, hadden ook een significant hoger risico op metastasen (tab. 5). In dit cohort hadden 57 patiënten bij baseline een PSAD $\geq$ 0,2 en $>2$ positieve biopten, en 7 ontwikkelden metastasen $(12 \%)$.
Figuur 2 Kaplan-Meier-curves van de duur van de AS

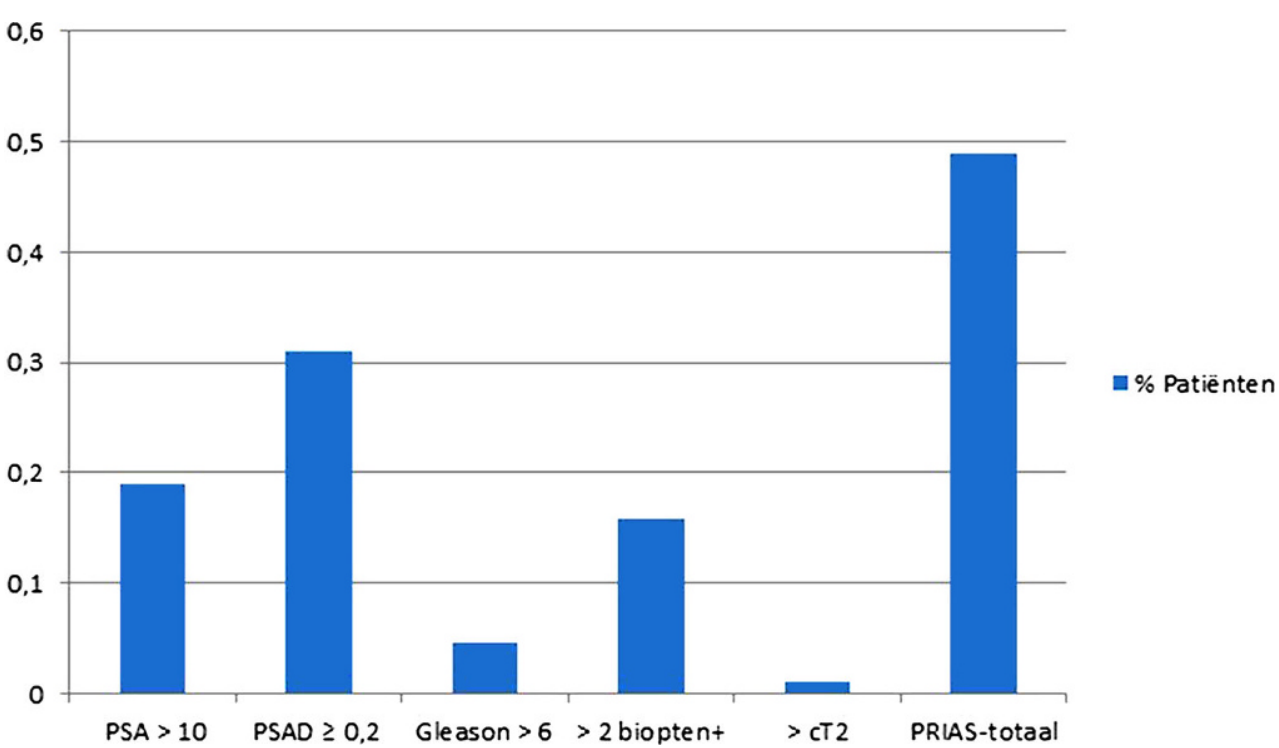


Tabel 3 Correlatie tussen PRIAS-criteria en tijd tot tumorprogressie

\begin{tabular}{|c|c|c|c|c|c|c|c|c|}
\hline & & \multirow{2}{*}{$\begin{array}{l}\text { Kaplan-Meier } \\
\text { duur } \mathrm{AS}^{\mathrm{d}}\end{array}$} & \multicolumn{3}{|c|}{ univariate Cox-regressieanalyse } & \multicolumn{3}{|c|}{ multivariate Cox-regressieanalyse } \\
\hline & & & hazardratio & $95 \%-B I$ & $p$ & hazardratio & $95 \%-\mathrm{BI}$ & $p$ \\
\hline leeftijd & jaren & & 0,99 & $0,98-1,01$ & 0,397 & 0,99 & $0,97-1,00$ & 0,088 \\
\hline PSA & $\begin{array}{l}>10 \\
\leq 10\end{array}$ & $\begin{array}{l}5,4 \\
6,0\end{array}$ & 1,12 & $0,88-1,41$ & 0,361 & - & - & - \\
\hline PSAD & $\begin{array}{l}\geq 0,2 \\
<0,2\end{array}$ & $\begin{array}{l}3,1 \\
7,3\end{array}$ & 2,03 & $1,67-2,45$ & $<0,001$ & 2,01 & $1,67-2,44$ & $<0,001$ \\
\hline Gleason & $\begin{array}{l}\geq 7 \\
\leq 6\end{array}$ & $\begin{array}{l}5,3 \\
6,0\end{array}$ & 1,35 & $0,89-2,05$ & 0,165 & - & - & - \\
\hline positieve biopten & $\begin{array}{l}>2 \\
\leq 2\end{array}$ & $\begin{array}{l}3,6 \\
5,6\end{array}$ & 1,62 & $1,28-2,06$ & $<0,001$ & 1,57 & $1,24-2,00$ & $<0,001$ \\
\hline PRIAS $^{\mathrm{b}}$ & $\begin{array}{l}\text { nee } \\
\text { ja }\end{array}$ & $\begin{array}{l}3,7 \\
6,4^{\mathrm{c}}\end{array}$ & 1,74 & $1,44-2,11$ & $<0,001$ & - & - & - \\
\hline aantal criteria & $\begin{array}{l}\geq 2 \\
\leq 1\end{array}$ & $\begin{array}{l}3,0 \\
6,8\end{array}$ & 1,78 & $1,42-2,22$ & $<0,001$ & - & - & - \\
\hline$\geq \mathrm{T} 3$ & $\begin{array}{l}\geq \mathrm{cT} 3 \\
\leq \mathrm{cT} 2^{\mathrm{d}}\end{array}$ & $\begin{array}{l}3,6 \\
5,9\end{array}$ & 1,28 & $0,48-3,44$ & 0,621 & - & - & - \\
\hline
\end{tabular}

${ }^{\text {a }}$ Mediane follow-up onder AS (time to event)

${ }^{\mathrm{b}}$ PRIAS: voldoen aan alle PRIAS-criteria $(\leq \mathrm{cT} 2$, PSA $\leq 10$, PSA-density $<0,20$; Gleason-score $\leq 6$ en $\leq 2$ positieve biopten)

${ }^{\mathbf{c}}$ Gemiddelde waarde, mediaan kon niet worden berekend, omdat $<50 \%$ van de populatie AS beëindigde binnen de studieperiode

${ }^{\mathrm{d}}$ mediaan in jaren

Tabel 4 Risico op ongunstige uitkomsten na uitgestelde radicale prostatectomie

\begin{tabular}{|c|c|c|c|c|c|c|c|c|}
\hline & $\begin{array}{l}\text { geen } \\
\text { zenuwsparing } \\
\text { OR }(95 \%-B I)\end{array}$ & $p$ & $\begin{array}{l}\text { positief snijvlak } \\
\text { OR }(95 \%-B I)\end{array}$ & $p$ & $\begin{array}{l}\text { ongunstige } \\
\text { histologie }^{\text {b }} \\
\text { OR }(95 \% \text {-BI) }\end{array}$ & $p$ & $\begin{array}{l}\text { biochemische } \\
\text { progressie } \\
\text { OR }(95 \%-\mathrm{BI})\end{array}$ & $p$ \\
\hline $\begin{array}{l}\text { PRIAS-ongeschikt } \\
\text { vs. PRIAS-geschikt }\end{array}$ & $1,49(0,73-3,03)$ & 0,269 & $\begin{array}{l}2,15 \\
(1,11-4,17)\end{array}$ & 0,023 & $3,20(1,61-6,35)$ & 0,001 & $1,98(0,75-5,23)$ & 0,168 \\
\hline $\mathrm{PSAD} \geq 0,2$ & $1,23(0,59-2,59)$ & 0,586 & $\begin{array}{l}1,97 \\
(1,03-3,79)\end{array}$ & 0,042 & $3,61(1,85-7,05)$ & $<0,001$ & $3,26(1,23-8,64)$ & 0,018 \\
\hline $\begin{array}{l}\text { positieve bi- } \\
\text { opten }>2\end{array}$ & $1,59(0,61-4,17)$ & 0,342 & $\begin{array}{l}2,96 \\
(1,26-6,94)\end{array}$ & 0,013 & $1,89(0,83-4,34)$ & 0,132 & $3,69(1,32-10,35)$ & 0,013 \\
\hline
\end{tabular}

${ }^{a}$ Geen zenuwsparing(omvat partieel, unilateraal en volledig niet zenuwsparend)

${ }^{\mathrm{b}}$ Ongunstige histologie, gedefinieerd als pT-stadium $\geq \mathrm{T} 3$ en/of Gleason-somscore $\geq 8$

Tabel 5 Risico op het ontwikkelen van metastasen per PRIAS-selectiecriterium

\begin{tabular}{lllc}
\hline & hazardratio & $95 \%$-BI & $p$ \\
\hline PSA $>10$ & 1,33 & $0,53-3,33$ & 0,546 \\
PSAD $\geq 0,2$ & 2,71 & $1,23-5,96$ & 0,014 \\
Gleason-somscore $\geq 7$ & 2,25 & $0,53-9,56$ & 0,273 \\
aantal positieve biopten $>2$ & 2,17 & $0,90-5,19$ & 0,083 \\
voor PRIAS ongeschikt & 1,37 & $0,62-3,01$ & 0,438 \\
niet voldoen aan $\geq 2$ PRIAS-criteria & 3,04 & $1,37-6,78$ & 0,006 \\
PSAD $\geq 0,2$ en $>2$ positieve biopten & 6,17 & $2,57-14,82$ & $<0,001$ \\
PSAD $\geq 0,2$ en PSA > 10 & 2,11 & $0,84-5,28$ & 0,112 \\
PSA $>10$ en $>2$ positieve biopten & 3,48 & $1,04-11,64$ & 0,043 \\
\hline
\end{tabular}

\section{Discussie}

In het Santeon-cohort van 1.000 patiënten die waren geïncludeerd voor AS, voldeed $49 \%$ niet aan een of meer van de PRIAS-criteria. Voor PRIAS ongeschikte patiënten ontwikkelden significant eerder tumorprogressie vergeleken met de voor PRIAS geschikte subgroep. Voor PRIAS onge- schikte patiënten hadden ook een hoger risico op ongunstige histologische en chirurgische uitkomsten na uitgestelde radicale prostatectomie. Op baseline een PSAD $\geq 0,20$ bleek een sterke individuele voorspeller van (ongunstige) AS-uitkomsten, eerdere tumorprogressie, een hoger risico op ongunstige uitkomsten na uitgestelde operatie en een hoger risico op metastasen. 
Een actueel onderwerp op het gebied van AS is de mate waarin de selectiecriteria zouden kunnen worden uitgebreid [9-11]. Hoewel er beperkte informatie beschikbaar is over de veiligheid van AS voor patiënten met een hoger-risico$\mathrm{PCa}$, geven de resultaten van dit onderzoek aan dat de 'indicatie' (op basis van gehanteerde selectiecriteria) in de dagelijkse praktijk al wordt verruimd. Deze bevindingen suggereren dat patiënten (en clinici) bereid zijn om potentiële overlevingswinst af te wegen tegen een behoud van (hogere) kwaliteit van leven.

Aan de andere kant zijn urologen mogelijk niet volledig op de hoogte van de mogelijke gevolgen van de selectie van patiënten met een hoger risico. Deze studie biedt aanvullende informatie die zeer relevant is voor clinici die deze patiënten begeleiden. Drie eerdere onderzoeken, die ook AS-uitkomsten van patiënten met een lager- en hogerrisico-PCa evalueerden, meldden een significant hoger risico op metastasen bij patiënten met een intermediair risico. Bul et al. rapporteerden bijvoorbeeld een 10-jaars metastasevrije overleving van $99,7 \%$ bij patiënten met een laag risico en $96,4 \%$ bij patiënten met een intermediair risico (log-rank $p=0,03$ ) [12]. In de studie van Godtman et al. werd gerapporteerd dat patiënten uit groep met een laag en intermediair risico een hogere kans hadden op een ongunstig AS-beloop (gedefinieerd als PCa-specifiek overlijden, PCa-metastase en/of biochemische progressie en/of initiatie van hormonale therapie na radicale behandeling) vergeleken met patiënten met een zeer laag risico $(\mathrm{HR}=4,8$; 95\%-BI = 2,44-9,33) [13]. Vergelijkbare resultaten werden gerapporteerd in een onderzoek binnen het Sunnybrook-cohort: Musunuru et al. rapporteerden dat patiënten met een intermediair risico een significant lagere 15-jaars metastasevrije overleving hadden vergeleken met patiënten met een laag risico $(\mathrm{HR}=3,14 ; 95 \%-\mathrm{BI}=1,51-6,53)$ [14].

Nyame et al. vonden daarentegen géén significant verschil in metastasevrije overleving tussen patiënten met intermediair/hoogrisico-PCa in vergelijking met patiënten met laagrisico-PCa $(\mathrm{HR}=1,50 ; 95 \%-\mathrm{BI}=0,16-14,5)$.

Onze studie is een aanvulling op de huidige literatuur, omdat we AS-uitkomsten hebben vergeleken in een realworld cohort, en daarbij de populatie hebben gestratificeerd in een voor PRIAS geschikte en een voor PRIAS ongeschikte subgroep. Daarnaast hebben we de associaties tussen ongunstige AS-uitkomsten en álle afzonderlijke PRIASinclusiecriteria op ongunstige uitkomsten geëvalueerd, hetgeen nieuwe informatie over de voorspellende waarde van elke afzonderlijke factor heeft verschaft.

Vergelijking van voor PRIAS ongeschikte met voor PRIAS geschikte patiënten gaf geen significant verschil met betrekking tot het risico op metastasen. Bij univariabele analyse bleek een PSAD $\geq 0,2$ echter wel een sterke individuele voorspeller voor het risico op metastasen. Deze factor is ook sterk geassocieerd met een hoger risico op andere ongunstige uitkomsten. Dit suggereert dat in het Santeon-cohort het gebruik van de PRIAS-criteriumclassificatie als geheel minder voorspellend was in vergelijking met een PSAD als factor alléén.

Het PRIAS-selectiecriterium 'een PSAD < 0,2' was tevens de factor waaraan het vaakst niet werd voldaan. Dit geeft aan dat urologen dit mogelijk als een minder belangrijk selectiecriterium voor AS beschouwen of mogelijk onvoldoende op de hoogte zijn van het feit dat de PSAD in sterke mate een bepalende factor is voor het ziektebeloop. Ook omvat de overgrote meerderheid van lopende prospectieve AS-studies (dat wil zeggen 7/9 studies; 78\%) de PSAD niet als een selectiecriterium [15]. Gezien de sterke associatie tussen PSAD en AS-uitkomsten in deze studie, wordt de voorspellende waarde van PSAD op ASuitkomsten mogelijk onderschat.

De voorspellende waarde van PSAD op AS-uitkomsten die uit deze studie blijkt, is in overeenstemming met de resultaten van eerdere onderzoeken. Zo zijn bijvoorbeeld de voorspellers van ongunstige histologische kenmerken onderzocht bij AS-kandidaten die allen een radicale prostatectomie hadden ondergaan. Uit deze studie bleek bijvoorbeeld dat een PSAD > 0,15 voorspellend was voor een Gleason-upgrade of een pathologisch stadium $\geq \mathrm{T} 3(\mathrm{OR}=2,04$; $95 \%-\mathrm{BI}=1,91-2,31)$ [16]. Daarnaast constateerde een andere onderzoeksgroep dat PSAD $>0,15$ sterk geassocieerd was met ongunstige pathologische bevindingen bij radicale prostatectomie [17]. In vier studies die zich concentreerden op het verband tussen baselinefactoren en ziekteprogressie bij patiënten met PCa bij AS, bleek PSAD ten tijde van de diagnose ook een sterke voorspeller van ziekteprogressie te zijn [18-21].

Het blijft de vraag of we nu kunnen zeggen dat het veilig is om de selectiecriteria voor AS uit te breiden op basis van eerdere resultaten en onze bevindingen, en zo ja, hoe ver we hierin kunnen gaan. Op basis van de data in deze studie lijkt AS in ieder geval een minder goede keuze voor patiënten met zowel een $\mathrm{PSAD} \geq 0,2$ als $>2$ positieve biopten ten tijde van diagnose, aangezien $12 \%$ van deze patiënten uiteindelijk PCa-metastasen ontwikkelde. Gegeven de relatief hoge incidentie van metastasen $(5 \%)$ onder patiënten met PSAD $\geq 0,2$ zou bij patiënten met deze risicofactor ook goed moet worden overwogen of AS wel de juiste keuze is.

Een belangrijke vraag die onbeantwoord blijft, is of de voor PRIAS ongeschikte patiënten beter af waren geweest als ze direct een curatieve behandeling hadden ondergaan in plaats van AS. Dit zou een interessant vraagstuk zijn om in toekomstig onderzoek te beantwoorden. Daarin zouden dan de uitkomsten van voor PRIAS ongeschikte patiënten onder AS kunnen worden vergeleken met een op casemix gematchte populatie die direct curatieve behandeling onderging. 
Deze studie kent een aantal sterke punten, omdat het een multicenter onderzoek is met een grote real-world populatie. Noemenswaardig is dat dit onderzoek tot stand is gekomen naar aanleiding van het lopende Santeon Value Based Healthcare initiatief, waarbij periodiek kwaliteitsindicatoren voor prostaatkankerzorg worden vergeleken tussen de ziekenhuizen. Huidig onderzoek is een van de wetenschappelijke initiatieven die zijn oorsprong heeft in dit initiatief. Wij moedigen andere centra dan ook van harte aan om soortgelijke initiatieven te starten dan wel te continueren, omdat ze inzichten opleveren die relevant zijn voor de klinische praktijk. De studie kent echter ook minder sterke kanten. Zo is het retrospectieve design van deze studie een beperking die kan hebben geleid tot informatiebias. Het is bijvoorbeeld mogelijk dat patiënten die eigenlijk onder watchful waiting stonden, werden gescoord als AS-patiënten. De percentages patiënten die een radicale behandeling ondergingen na beëindigen van AS waren echter vergelijkbaar tussen de voor PRIAS geschikte en de voor PRIAS ongeschikte subgroepen (73\% versus $73 \%$ ). Respectievelijk $11 \%$ van de voor PRIAS geschikte patiënten die stopten met AS schakelden over op watchful waiting. Dit percentage was $14 \%$ in de voor PRIAS ongeschikte groep. Gezien de praktisch vergelijkbare percentages in beide groepen, vonden we bias die onze studieresultaten zou kunnen hebben beïnvloed, weinig aannemelijk. Alle gegevens die door de dossiermedewerkers ingevoerd waren, zijn gecontroleerd door de hoofdonderzoeker en bij twijfel is de behandelend uroloog geraadpleegd. Ten tweede heeft de studie het risico van measurement bias, omdat niet alle patiënten tijdens de follow-up dezelfde diagnostische tests hebben ondergaan. Op deze manier kon een metastase alleen worden bevestigd bij patiënten die bijvoorbeeld een lymfeklierdissectie of -beeldvorming ondergingen. Dit kan hebben geleid tot onderschatting van het aantal patiënten met uitzaaiingen, doordat niet bij iedereen even extensief diagnostiek werd ingezet. Ten derde werden factoren die tevens van invloed zouden kunnen zijn geweest op het beloop, zoals continueren van AS ondanks significante tumorprogressie en de intensiteit van de follow-up, buiten beschouwing gelaten in deze studie.

\section{Conclusies}

Het afwegen van de voordelen van het uitstellen tot zelfs volledig vermijden van radicale behandeling van prostaatkanker, tegen het risico dat de tumor zich ontwikkelt tot een stadium met een slechtere prognose, is een belangrijk thema voor de patiënt en een dilemma voor de uroloog bij het selecteren van hoger-risicopatiënten voor AS. In het huidige cohort voldeed bijna de helft van alle AS-patiënten niet aan de PRIAS-criteria. Deze voor PRIAS ongeschikte patiënten die in deze studie zijn geselecteerd, hebben een snellere ziekteprogressie en een hoger risico op ongunstige uitkomsten na uitgestelde chirurgie. Een PSAD $\geq 0,2$ was een belangrijke individuele voorspeller van tumorprogressie en was geassocieerd met slechtere prognose.

Dankbetuiging Wij danken alle dossiermedewerkers, Wim van den Bosch (initiator van de Santeon Prostaatkanker database), en de Santeon-urologen voor hun ondersteuning tijdens de datacollectie in de ziekenhuizen. Dit onderzoek werd mede mogelijk gemaakt door onafhankelijke subsidies van Astellas Pharma en Amgen.

Open Access This article is distributed under the terms of the Creative Commons Attribution 4.0 International License (http:// creativecommons.org/licenses/by/4.0/), which permits unrestricted use, distribution, and reproduction in any medium, provided you give appropriate credit to the original author(s) and the source, provide a link to the Creative Commons license, and indicate if changes were made.

\section{Literatuur}

1. Cooperberg MR, Carroll PR, Klotz L. Active surveillance for prostate cancer: Progress and promise. J Clin Oncol. 2011;29(27): 3669-76.

2. Tosoian JJ, Mamawala M, Epstein JI, et al. Intermediate and longerterm outcomes from a prospective active-surveillance program for favorable-risk prostate cancer. J Clin Oncol. 2015;33(30):3379-85.

3. Hawken SR, Womble PR, Herrel LA, et al. Understanding the performance of active surveillance selection criteria in diverse urology practices. J Urol. 2015;194(5):1253-7.

4. Bul M, Zhu X, Valdagni R, et al. Active surveillance for lowrisk prostate cancer worldwide: the PRIAS study. Eur Urol. 2013;63(4):597-603.

5. Harris PA, Taylor R, Thielke R, Payne J, Gonzalez N, Conde JG. Research electronic data capture (REDCap) - a metadata-driven methodology and workflow process for providing translational research informatics support. J Biomed Inform. 2009;42(2):377-81.

6. Matulewicz RS, Weiner AB, Schaeffer EM. Active surveillance for prostate cancer. JAMA. 2017;318(21):2152.

7. Bergh RC van den, Roemeling S, Roobol MJ, Roobol W, Schroder FH, Bangma $\mathrm{CH}$. Prospective validation of active surveillance in prostate cancer: The PRIAS study. Eur Urol. 2007;52(6):1560-3.

8. Cookson MS, Aus G, Burnett AL, et al. Variation in the definition of biochemical recurrence in patients treated for localized prostate cancer: The american urological association prostate guidelines for localized prostate cancer update panel report and recommendations for a standard in the reporting of surgical outcomes. J Urol. 2007;177(2):540-5.

9. Tosoian JJ, Loeb S, Epstein JI, Turkbey B, Choyke PL, Schaeffer EM. Active surveillance of prostate cancer: Use, outcomes, imaging, and diagnostic tools. Am Soc Clin Oncol Educ Book. 2016;35:e235-e45.

10. Dall'Era MA, Klotz L. Active surveillance for intermediate-risk prostate cancer. Prostate Cancer Prostatic Dis. 2017;20(1):1-6.

11. Perlis N, Klotz L. Contemporary active surveillance: candidate selection, follow-up tools, and expected outcomes. Urol Clin North Am. 2017;44(4):565-74.

12. Bul M, Bergh RC van den, Zhu X, et al. Outcomes of initially expectantly managed patients with low or intermediate risk screendetected localized prostate cancer. BJU Int. 2012;110(11):1672-7.

13. Godtman RA, Holmberg E, Khatami A, Pihl CG, Stranne J, Hugosson J. Long-term results of active surveillance in the goteborg 
randomized, population-based prostate cancer screening trial. Eur Urol. 2016; https://doi.org/10.1016/j.eururo.2016.03.048.

14. Musunuru HB, Yamamoto T, Klotz L, et al. Active surveillance for intermediate risk prostate cancer: survival outcomes in the sunnybrook experience. J Urol. 2016;196(6):1651-8.

15. Tosoian JJ, Carter HB, Lepor A, Loeb S. Active surveillance for prostate cancer: current evidence and contemporary state of practice. Nat Rev Urol. 2016;13(4):205-15.

16. Vellekoop A, Loeb S, Folkvaljon Y, Stattin P. Population based study of predictors of adverse pathology among candidates for active surveillance with gleason 6 prostate cancer. J Urol. 2014;191(2):350-7.

17. Reese AC, Landis P, Han M, Epstein JI, Carter HB. Expanded criteria to identify men eligible for active surveillance of low risk prostate cancer at johns hopkins: A preliminary analysis. J Urol. 2013;190(6):2033-8.

18. Tseng KS, Landis P, Epstein JI, Trock BJ, Carter HB. Risk stratification of men choosing surveillance for low risk prostate cancer. J Urol. 2010;183(5):1779-85.

19. San Francisco IF, Werner L, Regan MM, Garnick MB, Bubley G, DeWolf WC. Risk stratification and validation of prostate specific antigen density as independent predictor of progression in men with low risk prostate cancer during active surveillance. J Urol. 2011;185(2):471-6.
20. Barayan GA, Brimo F, Begin LR, et al. Factors influencing disease progression of prostate cancer under active surveillance: A McGill university health center cohort. BJU Int. 2014;114(6b):E99-E104.

21. Mamawala MM, Rao K, Landis P, et al. Risk prediction tool for grade re-classification in men with favourable-risk prostate cancer on active surveillance. BJU Int. 2016; https://doi.org/10.1111/bju. 13608 .

drs. Timo F.W. Soeterik arts-onderzoeker

dr. Harm H.E. van Melick uroloog

dr. Lea M. Dijksman epidemioloog, senior adviseur Raad van bestuur St. Antonius ziekenhuis

prof. dr. Douwe H. Biesma voorzitter Raad van bestuur St. Antonius ziekenhuis

prof. dr. J.A. (Fred) Witjes uroloog

dr. Jean-Paul A. van Basten uroloog 